\title{
Apresentação. Sociologia digital - tópicos E ABORDAGENS TEÓRICO-METODOLÓGICAS DA PESQUisa SOCIAL NO SÉCULO XXI
}

\author{
Lara FACIOLI* \\ Felipe PADILHA ${ }^{* *}$
}

Este dossiê reúne um conjunto de reflexões produzidas por pesquisadores e pesquisadoras das humanidades, em especial, das Ciências Sociais, com foco em diferentes temas, agrupados em torno de uma visão sociológica sobre os usos sociais das mídias digitais na sociedade brasileira contemporânea.

Os artigos percorrem um conjunto diverso de questões fundamentadas em trabalhos de pesquisas empíricas. São investigações que partem de diferentes abordagens e recortes, orientados por configurações teórico-metodológicas específicas, mas que, em comum, buscam interrogar múltiplas dimensões das relações sociais digitalmente mediadas.

Esta apresentação oferece uma síntese a respeito de alguns elementos conceituais e teórico-metodológicos que consideramos relevantes na composição do campo da sociologia digital. Além disso, busca também jogar luz sobre alguns dilemas de uma área em formação, com vistas a apontar os limites de uma concepção determinista acerca da consolidação das tecnologias digitais em nosso cotidiano.

Os artigos reunidos neste volume não evidenciam respostas, manuais ou saídas preestabelecidas para os impasses que inevitavelmente surgem durante o processo de pesquisa. Assim sendo, nossa intenção é promover um espaço de

\footnotetext{
FURG - Universidade Federal do Rio Grande. Campus Carreiros. Grupo de Pesquisa em Sociologia Digital. Carreiros - Rio Grande - RS - Brasil. 96203-900 - larafacioli@yahoo.com.br. https://orcid. org/0000-0003-4054-9631.

* UFSCar - Universidade Federal de São Carlos. Centro de Educação e Ciências Humanas. Departamento de Sociologia. Pesquisador Associado ao NAMCULT/ UFSCar - Núcleo de Estudos em Ambiente, Cultura e Tecnologia. São Carlos - SP - Brasil. 13565905 - felipeapa@yahoo.com.br. https:// orcid.org/0000-0002-5511-7252.
} 
diálogo, reflexão e intercâmbio de conhecimentos e experiências sobre o tema, um convite para que o outros pesquisadores e outras pesquisadoras se aventurem e contribuam com esse conjunto diverso de reflexões a respeito da presença contínua e integrada das tecnologias digitais no mundo em que vivemos, sem deixar de considerar as implicações dessa presença para o fazer da pesquisa.

As mídias digitais descortinam um campo fértil de oportunidades para o exercício da imaginação sociológica (MILLS, 1972), na medida em que permitem a formulação de um novo conjunto de conexões entre aspectos relevantes para as discussões da Sociologia, ao longo do tempo, como a clássica relação entre indivíduo e coletividade. Não se trata de considerar exclusivamente o papel relevante que as tecnologias digitais desempenham nas sociedades, mas também de entender como o advento das mídias digitais impacta o próprio ofício da sociologia (NASCIMENTO, 2016).

Tecnologias digitais são recursos incorporados à vida social de uma maneira quase inimaginável até há poucos anos. Um dos marcos de popularização do acesso à internet no Brasil se localiza no ano de 2013, quando a então presidenta Dilma Rousseff assinou decreto que zerou as alíquotas da contribuição para o Programa de Integração Social (PIS) e a Contribuição para o Financiamento da Seguridade Social (Cofins), incidentes sobre a receita bruta decorrente da venda de smartphones; resultando na queda do preço dos equipamentos e no consequente aumento no consumo. A medida tornou os aparelhos produzidos em solo nacional mais acessíveis, o que contribuiu para consolidar o telefone celular como o principal meio de acesso à internet no país.

Vale ressaltar que no ano de 2020, enquanto elaboramos este dossiê, vivemos a pandemia da Covid-19, período que marca também uma série de transformações e que tem acentuado e acelerado o processo de aprofundamento da presença da tecnologia em nosso cotidiano.

O momento de crise sanitária que o país enfrenta, bem como suas implicações, permite-nos experenciar momentos históricos e epistemológicos em que a tecnologia ganha mais centralidade não somente em nosso dia a dia, mas também em nossos repertórios simbólicos, culturais e investigativos. Trata-se de uma coincidência que nos permite, de forma bastante viva, realizar um balanço deste campo de conhecimento.

Paradoxalmente, no Brasil, no ano de 2018 cerca de um quarto da população ainda não possuía acesso à internet (IBGE, 2020). Apesar disso, tecnologias como smartphones, tablets e computadores com acesso à rede têm se colocado como précondição para o acesso aos benefícios concedidos pelo governo, para a continuidade das atividades escolares, para a construção de rotinas de trabalho remoto e para manutenção de vínculos afetivos em situações de isolamento. 


\title{
Apresentação. Sociologia digital - tópicos e abordagens teórico- metodológicas da pesquisa social no século XXI
}

Ao analisar as desigualdades digitais, Nelly Oudshoorn e Trevor Pinch (2003) nos ajudam a compreender esse fenômeno, sustentando que o foco exclusivo no indivíduo como unidade de análise pode reforçar o abismo entre incluídos e excluídos digitais, o que contribui para a construção de uma compreensão simplificada das relações sociais.

Dessa perspectiva, a premissa binária que aponta aqueles que estão fora ou dentro da possibilidade de uso da tecnologia acaba por ocultar as diferentes matizes presentes no envolvimento com as mídias digitais, além de contribuir para eclipsar uma diversidade de clivagens e significados socioculturais que podem estar envolvidos com o não-uso de uma tecnologia (BAUMER et al., 2015).

A compreensão que opõe incluídos e excluídos, conectados e não-conectados, pouco contribui para um entendimento sobre a diversidade de desigualdades presumidas sob o termo "acesso", especialmente no Brasil. Dessa forma, partimos da compreensão de que o estudo sobre as relações entre tecnologia, cultura e sociedade envolve usos e não usos, conexões e desconexões, uma vez que a mídia não somente é performativa, como também modula e regula até mesmo o cotidiano não conectado ou dos sujeitos que a ela não têm acesso.

Com essas pontuações, abrem-se algumas questões: será que as transformações ensejadas pelas tecnologias digitais são suficientes para sustentar a construção de um novo campo de pesquisa social? Afinal, o que é o digital e quais são suas características?

Empregamos os termos "mídias digitais" ou "tecnologias digitais" de maneira intercambiável, como uma expressão "guarda-chuva" que busca cobrir tanto o conjunto de suportes técnicos de dispositivos conectados em rede quanto a própria rede. O digital coloca em evidência a dimensão sociotécnica das relações, ou seja, um conjunto articulado de práticas sociais, políticas e representações cujo desempenho depende da tecnologia.

\begin{abstract}
[Assim,] Quando falamos de tecnologia digital, frequentemente nos referimos às atividades e práticas que as pessoas fazem em conjunto com a tecnologia, e não às próprias tecnologias. A sociologia digital, portanto, coloca em primeiro plano as discussões em termos de sentimentos e emoções das pessoas, seus (des)prazeres e (in)sensibilidades ao encontrar tecnologias digitais durante o curso de suas vidas cotidianas (SELWYN, et al, 2016, p.5, tradução nossa) ${ }^{1}$.
\end{abstract}

\footnotetext{
1 No original: When we talk about digital technology we are often referring to the activities and practices that people do in tandem with technology, rather than the technologies themselves. Digital sociology therefore foregrounds discussions in terms of people's feelings and emotions, their (dis)pleasures and (in) sensitivities when encountering digital technologies during the course of their everyday lives. (SELWYN, N. et al. Toward a digital sociology of school. In: Daniels, J. et al (eds). Digital sociologies. Bristol: Policy Press, 2016, p.5).
} 
Por isso, não se trata de reunir um conjunto de análises centradas exclusivamente no digital, na internet, no smartphone ou no computador, ainda que, de certo modo, todos esses dispositivos estejam incluídos e articulados, inclusive na dimensão artesanal da pesquisa. Afinal, numa vida digitalizada, até mesmo o que conta como social, é cada vez mais representado por meio das tecnologias digitais (LUPTON, 2015). De outro modo, trata-se de levar a sério que o desenvolvimento e a expansão da computação, aliada à geração de dados através da mídia, representa uma oportunidade para a sociologia recalibrar conceitos, métodos e nossa compreensão do social (LATOUR, 2008).

Autoras contemporâneas como Deborah Lupton (2015) e Noortje Marres (2017), por caminhos diferentes, sublinham que o potencial renovador da sociologia digital reside no conjunto de questões que orbitam o debate em torno do qual deve ser o foco da área e quais métodos de pesquisa seriam os mais adequados à teorização e à pesquisa sociológicas contemporâneas. Dessa perspectiva, as relações sociotécnicas configuradas a partir das mídias digitais são vistas como geradoras de oportunidades, que permitem o estabelecimento de novas conexões entre tecnologias e práticas sociais, poder, economia, desigualdades, diferenças.

O digital se estabelece aprofundando a interdependência com os domínios sociais preexistentes, daí seu aspecto sociotécnico. A presença da tecnologia não afeta apenas práticas e áreas específicas da vida social, mas tem a capacidade de deslocar as relações entre ambas, gerando novas formas organizacionais. Marres (2017) chama atenção para o fato de que a digitalização contínua da sociedade não representa somente um importante tópico de investigação, mas também guarda o potencial para transformar o próprio papel que a pesquisa social desempenha na sociedade.

O interesse da sociologia pela tecnologia não é uma novidade. Podemos afirmar que seu surgimento enquanto disciplina acadêmica esteve atravessado por processos de transformações mediados pelas tecnologias. Debruçados sobre o contexto dos processos de industrialização e sobre, por exemplo, as novas relações de trabalho desenvolvidas com o advento das esteiras industriais, embora pese a não centralidade das tecnologias nas análises clássicas inferimos que, elas surgem como aparato técnico mediador de novas relações sociais.

Ainda que as mídias digitais não fossem possíveis no século XIX, as tecnologias do contexto industrial foram fundamentais para construir as que utilizamos hoje e alteraram, já naquele momento, relações sociais e a maneira de estabelecer a circulação de informações e de repertórios culturais. Da mesma forma, o advento da imprensa, do rádio e, posteriormente, da televisão é desse momento e se constitui enquanto base analógica antecedente do computador e das novas formas de circulação de informação. 


\section{Apresentação. Sociologia digital - tópicos e abordagens teórico- metodológicas da pesquisa social no século XXI}

A relação entre os cartões perfurados passíveis de leitura pelas máquinas de tear do século XVIII, aqueles utilizados para decifração de códigos durante a segunda Guerra Mundial, e os algoritmos que pautam nossos usos da rede no ano de 2020 nos permite pensar em termos de um continuum não somente entre o on e o off-line, mas entre os próprios aparatos técnicos que nunca são totalmente novos, muito menos desvinculados de interesses históricos.

As transformações tecnológicas que adentram o século XX e o fenômeno causador de uma virada epistemológica, chamada por Stuart Hall (1997) de centralidade da cultura, tensionam a teoria social e, fundamentalmente, a sociologia, de forma que seu repertório investigativo não pode ignorar o advento dessas mídias.

Pode-se verificar também que, ao menos desde meados da década de 1990, as ciências sociais têm demonstrado crescente interesse pela internet, desde o seu surgimento em contexto norte-americano. Conforme observado por Richard Miskolci e Fernando Balieiro (2018), em um balanço provisório a respeito da produção na área em solo nacional

[...] é possível afirmar que no contexto brasileiro se deu processo similar ao observado por Deborah Lupton na esfera acadêmica anglo-saxã, ou seja, nos estudos culturais (o que no caso brasileiro equivale, aproximadamente, à produção na área de comunicação e, em parte, na antropologia), predominou por cerca de uma década o interesse em cibercultura, enquanto, na sociologia, predominaram objetos mais próximos da "sociedade da informação" ou de uma "sociologia das tecnologias da informação". Segundo a socióloga australiana: "o foco 'ciber' dos estudos culturais enfatiza as dimensões futurísticas, de ficção científica das tecnologias computadorizadas enquanto termos referindo-se a 'tecnologias da informação' dirigem a atenção ao uso real, factual e utilitário de tais equipamentos para acessar informação" (MISKOLCI e BALIEIRO, 2018, p.138).

A perspectiva sociológica permite entender como tecnologias incluem práticas sociais e culturais específicas, que não são meramente técnicas, mas resultam de decisões e escolhas políticas, além de contribuir para a compreensão de problemáticas sociológicas mais amplas, como o papel que a tecnologia desempenha nos processos de mudança social (MACKENZIE e WAJCMAN, 1999) e a elaboração de categorias analíticas que permitam captar as articulações complexas entre tecnologia e sociedade (SASSEN, 2002).

Assim, empregamos o digital como um termo que comporta um conjunto de interações e relações sociais radicalmente condicionadas pela tecnologia, sem que isso implique em afirmar que tais relações sejam determinadas pela tecnologia. Desse modo, circunscrevemos um conjunto diversificado de práticas moldadas e engendradas, ao longo dos processos sociais, articulando forças econômicas, 
culturais, políticas e também pela distribuição do acesso aos recursos técnicos indispensáveis.

De acordo com Saskia Sassen (2017), não há economia puramente digital, nem comunidade totalmente virtual. Isso significa dizer que poder, contestação, desigualdade, hierarquia se inscrevem no espaço eletrônico e moldam a criação de programas, aplicativos, ferramentas, plataformas, hardwares e softwares. Em outros termos, as tecnologias digitais, assim como outros aparatos técnicos e tecnológicos não são invenções nascidas de um esforço científico individual, mas estão imersas no solo das relações sociais e de poder.

Um dos equívocos apontados pelas teorias do chamado determinismo tecnológico e pelo profetismo da aldeia global (MCLUHAN, 1990), construídas no contexto de surgimento das mídias comunicacionais dos anos de 1960 e retomadas a cada nova descoberta do ramo da tecnologia, consistiu em apresentar uma versão de leitura dessas tecnologias digitais que desconsiderava seus contextos de produção e seus interesses. Esse grupo de autores apontou para a suposta capacidade que esses aparatos teriam de "fazer coisas", de transformar a realidade e de promover mudanças positivas em nosso cotidiano e no cenário político.

A irrupção de Mashall McLuhan e seus estudos sobre comunicação nos anos de 1960, traz para os estudos de mídia um caráter quase que profético ao apontar para a suposta revolução trazida pela televisão, meio multissensorial que estimularia e possibilitaria a participação em uma cultura comum e em uma espécie de aldeia global democrática, na qual diferentes formas de relações seriam possíveis.

O conceito de ciberespaço, desenvolvido por Pierre Levy (2015), na década de 1990, momento de surgimento da internet e das mídias digitais, também carrega consigo uma perspectiva otimista de que a tecnologia se constituiria neste espaço aberto e em rede, de trocas e circulações integradoras. O espaço ciber, ou seja, aquele que está "lá", em linhas gerais, poderia ser diferente do "aqui", que está situado fora da tela e, portanto, estar on-line seria ocupar um espaço portador de inúmeras possibilidades.

As teorias sobre a tecnologia de caráter determinista, sobretudo aquelas criticadas por Raymond Williams (2016) ao analisar a televisão, partem do pressuposto de que uma tecnologia exerce efeito causal sobre o comportamento humano, aspecto que o autor considera ingênuo a respeito das mídias. De outro modo, para este autor, a questão que se coloca é como consideramos o modo como essa tecnologia será articulada com grupos específicos de interesse e dentro de determinadas ordens sociais?

Dessa forma, o aprimoramento de novas técnicas e ferramentas tecnológicas não acontece de forma autônoma em relação às forças sociais de uma sociedade. Para Donald MacKenzie e Judy Wajcman (1999) que observaram com atenção o contexto de surgimento e consolidação das mídias digitais e se debruçaram 


\section{Apresentação. Sociologia digital - tópicos e abordagens teórico- metodológicas da pesquisa social no século XXI}

fundamentalmente sobre análises amplas em torno da temática da Ciência e da Tecnologia, o desenvolvimento tecnológico seja ele qual for, via de regra, está atravessado pelo discurso problemático do mito do homem inventor:

Para entender a força desse argumento, é necessário ver o que há de errado com nossa noção comum, mas totalmente mistificada, do inventor heroico. De acordo com essa noção, grandes invenções ocorrem quando, em um flash de gênio, uma ideia radicalmente nova se apresenta quase pronta na mente do inventor. Esta maneira de pensar é reforçada pelas histórias populares sobre a tecnologia, nas quais a cada dispositivo está anexada uma data precisa e um homem particular (algumas são, de fato, as mulheres nas listas estereotipadas) a quem a invenção inspirada "pertence". (MACKENZIE; WAJCMAN, 1999, p.9, tradução nossa)2.

Essa percepção teve como contraponto a consolidação de um conjunto de reflexões do campo dos estudos culturais, da sociologia e da comunicação. A crítica ao determinismo tecnológico caminhou no sentido da concretização de um esforço em compreender as diversas forças que atuam no surgimento de uma nova tecnologias ou ferramenta.

Para autores como Mackenzie e Wajcman (1999), as ferramentas tecnológicas são moldadas em um processo social que não tem uma força dominante única. Assim, entendemos que a tecnologia disponível é o resultado de um conjunto complexo de relações sociais que envolvem ciência, técnica, Estado, mercado, pessoas, entre outros fatores. Como tal, da maneira que aponta Willians (2016), a história da tecnologia deve ser a história de sua distribuição, de sua institucionalização e de seus usos.

Considerar essa complexidade de fatores que engendram as mídias digitais nos permite inferir, com auxílio do sociólogo australiano Scott McQuire (2011, p.205), que a noção de aldeia global ou de ciberespaço separados de um suposto mundo real, desconsidera a contínua negociação de diferentes fluxos midiáticos que gerenciam as diferentes formas de participação em cada um deles.

A mídia digital com acesso à internet seria, portanto, um "espaço relacional", na medida em que leva em conta o local de acesso e a constante relação com outros espaços. Para uma análise sociológica das mídias isso implica pensar sobre como são construídas e negociadas fronteiras diversas como, por exemplo de classe social, gênero, local de acesso, questões raciais, nível de instrução, local de moradia, entre

\footnotetext{
2 No original: To understand the force of this argument, it is necessary to see what is wrong with our common, but wholly mystified, notion of the heroic inventor. According to that notion, great inventions occur when, in a flash of genius, a radically new idea presents itself almost ready-formed in the inventor's mind. This way of thinking is reinforced by popular histories of technology, in which to each device is attached a precise date and a particular man (few indeed are the women in the stereotyped lists) to whom the inspired invention 'belongs'. (MACKENZIE; WAJCMAN, 1999, p.9).
} 
outras diferenças, que estão postas no plano off-line e que produzem um tipo de estratificação digital.

Saskia Sassen (2002), em diálogo com a concepção de modelagem social das tecnologias, aponta a necessidade de observar as condições materiais dentro das quais essas tecnologias operam, uma vez que elas são incorporadas a uma estrutura de poder real que envolve processos sociológicos e econômicos globais, mas também relações locais e no interior das cidades.

O peso do contexto na produção de uma tecnologia, assim como dos mitos que circundam seu desenvolvimento, fica evidente no momento atual de produção deste dossiê. Reativamos uma série de discursos e práticas a respeito da presença da tecnologia em nosso cotidiano, fundamentalmente por conta dos efeitos da pandemia da Covid-19, exemplo que mobilizamos aqui e que, muito provavelmente, constituirse-á enquanto marco histórico de avanço, tanto de ferramentas quanto de repertórios midiáticos e novas subjetividades. A epidemia, que até o dia 14 de julho de 2020, tinha mais de 13 milhões de contaminados e quase 600 mil mortos no mundo, impulsionou por conta de quarentenas totais e parciais, atividades com a utilização intensa de celulares e computadores com conexão à internet.

Há quem diga que a pandemia adiantou em anos o processo de entrada dessas tecnologias em nosso cotidiano e do recolhimento de dados pessoais expostos na rede. O Twitter, por exemplo, anunciou em maio de 2020 (G1, 2020) que os funcionários que desejassem trabalhar em casa para sempre poderiam optar pelo trabalho remoto.

De forma bem simples, enquanto setores da economia estiveram parados e tiveram que alterar sua rotina, o Vale do Silício parece ter como promessa um caminhar bastante lucrativo por meio das possibilidades de desenvolvimento de tecnologias para o desenvolvimento de home office, para consumo em massa de produtos culturais via plataformas streaming e pela forte investida de grupos interessados na consolidação de ferramentas de Educação a Distância. São novas relações cotidianas que podem ser pensadas como um capitalismo de softwares, de dados e de plataformas, como bem apontou Sérgio Amadeu da Silveira (2019):

A primeira característica dessa fase seria o papel de intermediação que as plataformas possuem. Elas se posicionam como um local que dá uma série de vantagens para que as transações aconteçam e, desse modo, obtêm dados de quem oferece e de quem procura algum bem ou serviço. A segunda característica fundamental é que as plataformas são dependentes dos "efeitos de rede": quanto mais numerosos os usuários de uma plataforma, mais valiosa ela é para todos os outros. As plataformas são grandes devoradoras de dados e, como se fossem ruminantes digitais, os entregam em amostras específicas para cada um dos anunciantes ávidos por obter, se possível em tempo real, um bom resultado em 


\section{Apresentação. Sociologia digital - tópicos e abordagens teórico- metodológicas da pesquisa social no século XXI}

sua transação, seja ela a oferta de um táxi, a resposta à busca de um namorado ou namorada, o aluguel de um imóvel na praia ou a venda de um móvel antigo, etc. O capitalismo de plataforma é um capitalismo de dados tratados por algoritmos. (SILVEIRA, 2019, p.24).

A intensificação de uso dessas mídias, neste momento, fez crescer a disputa em torno dos discursos adequados para pensar sua presença nos diversos setores da vida diária. Apesar das críticas e de diversas formas de resistência, fortaleceu-se a percepção de que as mídias digitais com acesso à internet salvariam a quarentena ao conectar pessoas situadas em pontos distantes, desenvolver trabalho remoto sem "quebrar" totalmente a economia fragilizada pela pandemia e educar as crianças com atividades suplementares transmitidas por professores e professoras, de forma on-line.

Nesse contexto, no Brasil da pandemia, podemos mencionar um exemplo significativo do que chamamos de Modelagem Social da Tecnologia, a criação do Centro de Mídias da Educação de São Paulo (CMSP). O Centro tem como objetivo a manutenção de atividades remotas para os estudantes da Educação Básica de São Paulo e foi elaborado, juntamente a um aplicativo destinado a professores e estudantes, cujo intuito era o compartilhamento de conteúdos educacionais. De acordo com o material distribuído pelo governo do estado de São Paulo e pela Secretaria de Educação, para inaugurar o CMSP em um curto período de tempo e disponibilizar conteúdos de qualidade e ao vivo, o governo contou com a parceria de empresas como Instituto Lemann, Fundação Roberto Marinho, Amazon, Claro, Tim, Vivo, Oi.

Muito embora seja possível mapear um conjunto de elogios e crenças divulgadas, mesmo entre docentes, de que a plataforma seja a maneira mais eficaz de não deixar os estudantes à própria sorte, a simples observação das parcerias nos permite perceber, embora de maneira superficial, o campo de interesses em jogo na elaboração de um aplicativo como esse.

De acordo com a socióloga Jose Van Dijck (2016), o aspecto mercadológico que atravessa as mídias, marca também uma mudança de interfaces e a passagem do que chamamos de web 2.0 para a web 3.0 ou web semântica. Ao contrário do aspecto de conexão entre um ponto e outro, garantida pela web 1.0, aquela do advento da internet, as web’s 2.0 e 3.0 são intermediadas pelas corporações que promovem o fenômeno que a autora chama de conectividade. Na web que consumimos atualmente, a Web Semântica, não se trata simplesmente de usuários conectados uns aos outros elaborando seus conteúdos, de acordo com seus interesses pessoais e privados, e sim de uma dinâmica que mobiliza dados produzidos sobre o uso, direcionando-os para a publicidade e, consequentemente, para o consumo. 
Para Van Dijck (2016), o desenvolvimento de uma configuração que congrega técnica com interesses econômicos, não pode ser pensada sem que se avalie a consolidação da mediação por meio de plataformas como Facebook, Twitter, Youtube e Linkedin. A interligação das plataformas com os usuários e entre as próprias plataformas compõe o que a autora chama de ecossistema dos meios conectivos. Tal ecossistema faz com que, mesmo que não estejamos conectados a algumas delas, nossos dados trafeguem e sejam recolhidos e redirecionados a elas.

As plataformas maiores e mais influentes - Facebook, Twitter, YouTube e LinkedIn - viveram uma verdadeira explosão na quantidade de usuários e em seu potencial de gerar dinheiro e o mesmo ocorreu com uma incontável quantidade de sítios menores, tanto comerciais, quanto sem fins lucrativos. A interconexão dessas plataformas teve como resultado a emergência de uma nova infraestrutura: um ecossistema dos meios conectivos, conformado por peixes grandes e outros nem tanto. Este passo de uma comunicação em rede a uma socialidade moldada por plataformas, e de uma cultura participativa a uma verdadeira cultura da conectividade, ocorreu em um breve lapso de tempo de não mais de dez anos. (VAN DIJCK, 2016, p.19, tradução nossa). ${ }^{3}$

Os ecossistemas em rede conectam plataformas e usuários a interesses mais amplos, que envolvem corporações e que extrapolam contextos nacionais. Como nos alerta Sassen (2002), tais interesses se expressam por meio de estruturas de poder que não são apenas globais, mas também locais. No caso do brasileiro em tela, em especial, no caso da plataforma educacional paulista que utilizamos como ilustração, tanto ela quanto as empresas parceiras estão inseridas num quadro geopolítico, econômico e social, que não pode deixar de ser considerado em sua complexidade. As investigações sobre os fenômenos digitalmente mediados expressam relações que, em larga medida, expressam a composição da sociedade brasileira e as relações que a atravessam.

Nesse sentido, consideramos que nosso esforço dialógico de apresentar um conjunto de textos de autores e autoras nacionais que compõem o campo da sociologia digital, tem como objetivo ampliar o debate a respeito do caráter político da tecnologia, evidenciando sua dimensão sociotécnica em sua articulação com

\footnotetext{
3 No original: Las plataformas más grandes e influyentes - Facebook, Twitter, YouTube y LinkedInvivieron una verdadera explosión en la cantidad de usuarios y en su potencial de generar dinero, y lo mismo ocurrió con una incontable cantidad de sitios más pequeños, tanto comerciales como sin fines de lucro. La interconexión de estas plataformas tuvo por resultado la emergencia de una nueva infraestructura: un ecosistema de medios conectivos, conformado por peces gordos y otros no tanto. Este paso de una comunicación en red a una socialidad moldeada por plataformas, y de una cultura participativa a una verdadera cultura de la conectividad, ocurrió en un breve lapso temporal de no más de diez años. (VAN DIJCK, 2016, p.19).
} 


\section{Apresentação. Sociologia digital - tópicos e abordagens teórico- metodológicas da pesquisa social no século XXI}

dinâmicas de poder, controle e desigualdades que ganham novas cores a partir dos contextos em que se inserem.

Em certa medida, as pesquisas empíricas que compõem este volume questionam as explicações deterministas a respeito da tecnologia e compreendem que a cultura e o social tanto resultam das tecnologias, quanto moldam o que elas irão produzir. Em comum, os artigos não partem da presunção da existência de um espaço on-line desconectado da realidade face a face, uma vez que consideram tanto a ubiquidade das tecnologias em nosso contexto, quanto entendem que elas são performativas, regulam e moldam relações sociais de conexão e desconexão.

As investigações comportam análises de plataformas, de diálogo com usuários interlocutores de pesquisa e refletem sobre os usos, sobre estruturas algorítmicas, sobre forças políticas e econômicas que as engendram, dentre outros aspectos. Os textos apresentam uma percepção do digital em sua complexidade enquanto relação social e aportam problemáticas teóricas, mas também inovações metodológicas que inspiram a sociologia na reconfiguração de seus aparatos de pesquisa.

Assim, iniciamos pela temática da polarização política, especificamente, da formação de antagonismos discursivos em interações digitais que caracterizou o período das eleições brasileiras de 2018. Baseados em uma bibliografia robusta e contemporânea, Otávio Vinhas, Nilton Sainz e Raquel Recuero articulam no artigo Antagonismos Discursivos nas Hashtags \#Marqueteirosdojair e \#Bolsolão no Twitter nas Eleições de 2018 no Brasil: Contribuições da Análise de Redes Sociais à Sociologia Digital, softwares especializados na análise de redes sociais na internet à Teoria do Discurso para analisar as conexões e controvérsias desdobradas a partir do compartilhamento das hashtags \#MarqueteirosDoJair e \#Bolsolão, no Twitter, durante o período da disputa eleitoral.

As hashtags, pontos nodais formados por um agrupamento de interações que se caracterizam por muita similaridade e, portanto, são examinadas como discursos articulados. O artigo levanta questões pertinentes a respeito das chamadas "bolhas de opinião", caracterizadas pela redundância nas interações reiterando uma mesma posição. $\mathrm{O}$ artigo revela como os debates não estão exclusivamente restritos às redes digitais ao compreender a polarização política como um fenômeno dinâmico, contingente e contraditório, sustentada por discursos articulados digitalmente. As redes expressam debates que articulam continuamente as dimensões on e off-line.

Sérgio Amadeu da Silveira, no artigo Discursos Sobre Regulação e Governança Algoritmica, analisa os impasses decorrentes da adoção generalizada de sistemas algorítmicos que dão suporte a instrumentos como Big Data e Inteligência Artificial. $\mathrm{O}$ artigo examina as práticas discursivas presentes nas principais pesquisas sobre a regulação e a governança dos algoritmos, identificando os riscos e benefícios decorrentes da implementação generalizada desses sistemas, compreendidos como práticas de regulação e controle. 
O tema dos algoritmos e sua relação com os mercados e a política é retomado ao longo da sua entrevista Colonialismo tecnológico ou como podemos resistir ao novo eugenismo digital. O diálogo oferece um panorama a respeito de avanços teórico-metodológicos, mudanças recentes nas legislações nacionais, o impacto das mídias digitais nas eleições brasileiras de 2018 e as consequências decorrentes do ingresso da tecnologia na educação em tempos de pandemia.

Percorrendo as conexões entre política e tecnologia Luiz Augusto Mugnai Vieira Junior e Larissa Pelúcio ampliam o debate no texto Memes, Fake News e Pós-Verdade ou Como a Teoria de Gênero Vira uma "Ideologia Perigosa" ao incluir a dimensão das disputas em torno do gênero, além de trazer o poder dos afetos nas relações digitalmente mediadas. No caso do gênero, igualmente marcado por valores e questões morais conflitantes e antagônicas, o poder discursivo não se expressa através de hashtags, mas de memes. Metaforicamente compreendidos como poderosas armas de guerra, ideologicamente orientados pelo seu caráter sintético, os memes se expressam como argumentos visuais prontamente decodificáveis, daí sua eficácia.

Larissa Pelúcio e Luiz Augusto Mugnai Vieira Junior observam que "os memes e as fake news não são inverdades, são discursos e, portanto, contemplam efeitos de verdades". No caso do gênero, tais ferramentas discursivas revelam seu poder na medida em que demonstram a capacidade de reavivar antigas crenças e medos que emergem diante da expansão dos direitos humanos e dos estudos de gênero e sexualidade no Brasil.

$\mathrm{Na}$ esteira do gênero e dos afetos, Juliana do Prado analisa as relações entre mídias digitais e apoio emocional no artigo Nas Empresas de Garagem: Reflexões Sobre Masculinidades, Empreendedorismo e Mídias Digitais, tendo como foco específico as articulações e sentidos vinculados às masculinidades em rede. Com base em entrevistas com homens autodeclarados brancos, heterossexuais e profissionais liberais, selecionados a partir de uma rede on-line, a pesquisa mostra como a consolidação da comunidade ocorre mediante relações e vínculos estabelecidos entre homens que encontram um espaço para lidar com as inseguranças profissionais e com os impactos de tais inseguranças nas convenções e sentidos de masculinidades.

A rede de socialidade possibilita que os sujeitos sejam empreendedores de si enquanto buscam transformarem-se em homens socialmente admirados por suas conquistas no trabalho e nas relações afetivas. Nesse sentido, a comunidade pode ser entendida como um dos elementos envolvidos na modelagem social de uma masculinidade baseada em um modelo de negócios de apoio emocional, direcionado para homens com um perfil específico de classe social, sexualidade e raça.

O ensaio de Breilla Zanon, Depois do Pós-Fordismo: As Últimas Décadas da Razão Material do Trabalho, avança na reflexão sobre subjetividade e afetos 


\section{Apresentação. Sociologia digital - tópicos e abordagens teórico- metodológicas da pesquisa social no século XXI}

relacionados às incertezas do mercado de trabalho contemporâneo decorrentes, sobretudo, das novas dinâmicas de produção e organização dos trabalhadores. O ensaio apresenta como as gerações nascidas em meio às transformações do trabalho pós-fordista e o caráter empreendedor, a flexibilidade, a adaptação e a busca constante por inovação, posicionadas como questões-chave para a empregabilidade, emergem de maneira naturalizada.

As conexões produzidas pelo ensaio revelam como o espírito empreendedor, cuja expressão mais bem acabada pode ser observada a partir da organização e gestão do trabalho em startups e coworkings, apresenta-se como uma transfiguração do espírito do capitalismo flexível. A flexibilidade requer uma subjetividade, uma forma de interpretar o mundo do trabalho e as maneiras de se posicionar frente a um vínculo cada vez mais frágil, sustentado por novos arranjos e modalidades de disponibilidade e responsabilização dos trabalhadores.

Encerrando a publicação, Glauco Arbix e Rodrigo Brandão contribuem com a resenha do livro The Age of Surveillance Capitalism: The Fight for a Human Future at the New Frontier of Power, de autoria de Shoshana Zuboff. Além da contribuição para a agenda de pesquisa da sociologia digital, os autores destacam a importância do livro para a compreensão das características centrais da formação e do comportamento das redes sociais; para a percepção a respeito da concentração de poder nas mãos de poucas corporações e também as consequências dessa configuração para a democracia, o que recoloca o tema da regulação pública e da elaboração de mecanismos de controle para a atuação das gigantes tecnológicas.

Esperamos que este dossiê se construa enquanto espaço de diálogo e inspiração para o campo da Sociologia, fundamentalmente, na compreensão de que o digital, enquanto relação social, se coloca como um caminho sem volta a ser percorrido de forma investigativa na compreensão da sociedade contemporânea. Agradecemos aos autores e autoras e, principalmente, à Revista Estudos de Sociologia e à comissão editorial e seus colaboradores pelo espaço disponibilizado.

Boa leitura.

\section{REFERÊNCIAS}

BAUMER, E. P. S.; AMES, M. G; BURRELL, J. BRUBAKER, J. R.; DOURISH, P. Why study technology non-use? First Monday, v. 20, n. 11, 2015. Disponível em: http://dx.doi. org/10.5210/fm.v20i11.6310. Acesso em: 20 mai. 2020.

G1. Twitter afirma que funcionários poderão trabalhar de casa 'para sempre'. Publicado em 12 de maio de 2020. Globo.com. Disponível em: https://g1.globo.com/economia/tecnologia/ noticia/2020/05/12/twitter-afirma-que-funcionarios-poderao-trabalhar-de-casa-para-sempre. ghtml. Acesso em: 16 jul. 2020. 
HALL, S. A centralidade da cultura: notas sobre as revoluções culturais do nosso tempo. Educação \& Realidade, Porto Alegre, v. 22, n. 2, p.15-46, jul./dez. 1997. Disponível em: https://seer.ufrgs.br/educacaoerealidade/article/view/71361/40514. Acesso em: 20 mai. 2020.

IBGE. Diretoria de Pesquisas, Coordenação de Trabalho e Rendimento. Pesquisa Nacional por Amostra de Domicílios Contínua 2017-2018. 2020. Disponível em: https://biblioteca. ibge.gov.br/visualizacao/livros/liv101705_informativo.pdf. Acesso em: 16 jul. 2020.

LATOUR, B. Reensamblar lo social. Ediciones Manantial: Buenos Aires, 2008.

LÉVY, P. A inteligência coletiva. São Paulo, Folha de S.Paulo, 2015.

LUPTON, D. Digital Sociology. Nova Iorque: Routledge, 2015.

MACKENZIE, D.; WAJCMAN, J. (eds) The social shaping of technology. 2nd ed. Open University Press, Buckingham, UK. 1999.

MARRES, N. Digital Sociology: the reinvention of social research. Malden, MA: Polity, 2017.

MCLUHAN, Marshal. Pour comprendre les medias. Les prolongments technologiques de l'homme. Paris: Seuil, 1990.

MCQUIRE, S. A casa estranhada. Revista ECO-Pós, v. 14, n. 1, p.195-232, 2011. Disponível em: https://revistaecopos.eco.ufrj.br/eco_pos/article/view/919. Acesso em: 16 jun. 2020.

MILLS, C. W. A imaginação sociológica. Rio de Janeiro: Zahar, 1972.

MISKOLCI, R.; BALIEIRO, F. F. Sociologia Digital: balanço provisório e desafios. Revista Brasileira de Sociologia. v. 06, n. 12, p. 132-156, jan./abr, 2018. Disponível em: http:// dx.doi.org/10.20336/rbs.237. Acesso em: 15 abr. 2020.

NASCIMENTO, L. F. A Sociologia Digital: um desafio para o século XXI. Sociologias [online]. v. 18, n. 41, 2016, p.216-241. Disponível em: https://doi.org/10.1590/15174522018004111. Acesso em: 15 jul. 2020.

OUDSHOORN, N.; PINCH, T. Introduction: how users and non-users matter. In: OUDSHOORN, N.; PINCH, T. (Orgs.). How Users Matter The Co-Construction of Users and Technologies. Londres: MIT PRESS, 2003.

SASSEN, S. Preface. In: DANIELS, J.; GREGORY, K.; COTTOM, T. M. (eds.). Digital Sociologies. Bristol: Policy Press. E-book, 2017.

SASSEN, S. Towards a Sociology of Information Technology. Current Sociology, v. 50, n. 3, p.365-388, 2002. Disponível em: http://www.saskiasassen.com/PDFs/publications/ Towards-a-Sociology-of-Information-Technology.pdf. Acesso em: 24 abr. 2020. 
SELWYN, N.; NEMORIN, S.; BULFIN, S.; JOHNSON, N. Toward a digital sociology of school. In: DANIELS, J.; GREGORY, K.; COTTOM, T. M. (eds.). Digital Sociologies. Bristol: Policy Press. E-book, 2016.

SILVEIRA, S. A. Democracia e os Códigos Invisíveis - como os algoritmos estão modulando comportamentos e escolhas políticas. São Paulo: Edições Sesc, 2019.

VAN DIJCK, José. La cultura de la conectividad: una historia de las redes sociales. Buenos Aires: Siglo Veintiuno, 2016.

WILLIAMS, Raymond. Televisão: tecnologia e forma cultural. Trad. Márcio Serelle; Mário F. I. Viggiano. 1 ed. São Paulo: Boitempo; Belo Horizonte: PUC Minas, 2016. 
